\title{
BMJ Open Communicative characteristics of general practitioner-led and nurse-led telephone triage at two Danish out-of- hours services: an observational study of 200 recorded calls
}

\author{
Emil Vilstrup, ${ }^{1}$ Dennis Schou Graversen, ${ }^{1,2}$ Linda Huibers, ${ }^{1}$ \\ Morten Bondo Christensen, ${ }^{1,2}$ Anette Fischer Pedersen ${ }^{\odot 1,3}$
}

To cite: Vilstrup E,

Graversen DS, Huibers L, et al. Communicative characteristics of general practitioner-led and nurse-led telephone triage at two Danish out-of-hours services: an observational study of 200 recorded calls. BMJ Open 2019;9:e028434. doi:10.1136/ bmjopen-2018-028434

\section{- Prepublication history for} this paper is available online. To view these files, please visit the journal online (http://dx.doi. org/10.1136/bmjopen-2018028434).

Received 7 December 2018 Revised 15 April 2019 Accepted 10 May 2019

A Check for updates

(c) Author(s) (or their employer(s)) 2019. Re-use permitted under CC BY-NC. No commercial re-use. See rights and permissions. Published by BMJ.

${ }^{1}$ Research Unit for General Practice, Aarhus University, Aarhus, Denmark ${ }^{2}$ Department of Public Health, Aarhus University, Aarhus, Denmark

${ }^{3}$ Department of Clinical Medicine, Aarhus University, Aarhus, Denmark

Correspondence to

Emil Vilstrup;

emilvild@gmail.com

\section{ABSTRACT}

Objectives Out-of-hours $(\mathrm{OOH})$ telephone triage is used to manage patient flow, but knowledge of the communicative skills of telephone triagists is limited. The aims of this study were to compare communicative parameters in general practitioner (GP)-led and nurseled $\mathrm{OOH}$ telephone triage and to discuss differences in relation to patient-centred communication and safety issues.

Design Observational study.

Setting Two Danish $00 \mathrm{H}$ settings: a large-scale general practitioner cooperative in the Central Denmark Region ( $n=100 \mathrm{GP}$-led triage conversations) and Medical Helpline 1813 in the Capital Region of Denmark ( $n=100$ nurse-led triage conversations with use of a clinical decision support system).

Participants 200 audio-recorded telephone triage conversations randomly selected.

\section{Primary and secondary outcome}

measures Conversations were compared with regard to length of call, distribution of speaking time, question types, callers' expression of negative affect, and nurses' and GPs' responses to callers' negative affectivity using the MannWhitney U test and the Student's t-test.

Results Compared with GPs, nurses had longer telephone contacts ( $137 \mathrm{~s}$ vs $264 \mathrm{~s}, \mathrm{p}=0.001$ ) and asked significantly more questions (5 vs 9 questions, $p=0.001$ ). In $36 \%$ of nurse-led triage conversations, triage nurses either transferred the call to a physician or had to confer the call with a physician. Nurses gave the callers significantly more spontaneous talking time than GPs (23.4s vs $17.9 \mathrm{~s}, \mathrm{p}=0.01)$. Compared with nurses, GPs seemed more likely to give an emphatic response when a caller spontaneously expressed concern; however, this difference was not statistically significant $(36 \%$ vs $29 \%, p=0.6)$.

Conclusions When comparing communicative parameters in GP-led and nurse-led triage, several differences were observed. However, the impact of these differences in the perspective of patient-centred communication and safety needs further research. More knowledge is needed to determine what characterises good quality in telephone triage communication.

\section{Strengths and limitations of this study}

- This is the first study to thoroughly compare communicative parameters between general practitioners and nurses in out-of-hours $(\mathrm{OOH})$ services.

- Use of randomly selected, real-life triage contacts reflects the diversity and challenges the triagist meets in an $\mathrm{OOH}$ service.

- The study used clear definitions of communicative parameters.

- The study lacked information on call handlers (eg, age, sex) and patients' reasons for enquiry.

- One rater scored all contacts, but a pilot study of five randomly selected triage calls with two independent raters revealed near-complete agreement between the raters, and two raters discussed all registered expressions of negative affect.

\section{BACKGROUND}

Telephone triage (TT) at out-of-hours $(\mathrm{OOH})$ centres is a well-established system in many Western countries. ${ }^{1}$ TT is used to handle patient flow and ultimately evaluate patients' need for medical attention and ensure that patients are allocated to the right level of care, which are important elements of patient safety and efficiency. ${ }^{23}$ According to the WHO, patient safety can be defined as the absence of preventable harm to a patient during the process of healthcare and reduction of risk of unnecessary harm associated with healthcare to an acceptable minimum. ${ }^{4}$ It has proven to be efficient and cost-saving for health systems. ${ }^{56}$ A study found that the introduction of TT increased the number of telephone contacts to the $\mathrm{OOH}$ centres, but also reduced the need for clinic consultations and home visits performed by general practitioners (GPs). ${ }^{7}$ 
Although TT is frequently used, knowledge of the communicative skills of telephone triagists is limited, and there seems to be no agreement on indicators of what characterise good quality in TT. ${ }^{8}$ Studies have identified failure to listen to the caller and inappropriate handling of the caller's worry as frequent threats to patient safety. ${ }^{2} 1011$ Other studies comparing GP-led and nurse-led TT have mainly focused on call length and questioning. One study found that GPs and nurses have similar call length, ${ }^{12}$ whereas another study found nurses to have longer calls. ${ }^{6}$ One study found nurses to mainly ask closed-ended questions, ${ }^{2}$ and another study found nurses to ask more questions compared with GPs. ${ }^{12}$ Differences in questioning and call length between GPs and nurses may be explained by nurses' use of computer decision support software (CDSS). ${ }^{12}{ }^{13}$ One study found call length to correlate with the quality of communication, and studies have mentioned short calls as a potential risk to patient safety. ${ }^{214}$

An increasing workload in $\mathrm{OOH}$ services and shortage of GPs have induced a reorganising of the $\mathrm{OOH}$ centres in many countries, including replacing GP-led with nurse-led triage. ${ }^{75-17}$ Studies have suggested nurse TT to decrease the GP workload in primary care ${ }^{18}{ }^{19}$ In the Capital Region of Denmark, the OOH system in 2014 was replaced by the Medical Helpline 1813 (MH-1813), mainly using nurses to perform the triage. ${ }^{20}$ Consequently, the situation in Denmark enables a unique comparison of OOH TT conducted by either a nurse using CDSS or a GP in two presumably similar patient populations.

The aim of this study was to compare communicative parameters in TT performed by GPs and nurses. We specifically examined length of call, ${ }^{6}{ }^{12}$ spontaneous talking time, ${ }^{21}$ question types, ${ }^{2}{ }^{12}$ and callers' expression of negative affect and triagists' response to negative affect. $^{2}{ }^{10}$ The following were the study hypotheses: TT nurses have longer telephone contacts, give the caller more spontaneous talking time before interrupting and respond more emphatic to callers' expression of concern compared with TT GPs. Due to mixed previous findings regarding questioning technique, this aspect was examined as a research question: How does use of open-ended and closed-ended questions associate with profession?

\section{METHODS \\ Design}

We conducted an observational study assessing 200 audio-recorded TT conversations (100 with nurses and 100 with GPs) from two OOH care services in Denmark on a list of communicative quality indicators. This study was nested within a larger scale study assessing communication, patient safety and efficiency of 1950 randomly selected TT calls from two Danish health regions: the Central Denmark Region and the Capital Region of Denmark. $^{22}$

\section{Patient and public involvement}

Patients were not involved through use of recordings of real-life calls to $\mathrm{OOH}$ services. The findings of the study will be shared with the public to whom quality of $\mathrm{OOH}$ services is of high importance.

\section{Setting}

In Denmark, the $\mathrm{OOH}$ services are organised in five administrative regions. Four out of five regions, including Central Denmark Region, have a general practitioner cooperative (GPC) delivering $\mathrm{OOH}$ care with GPs performing the TT. In 2014, it was politically determined to replace the $\mathrm{OOH}$ service in the Capital Region of Denmark with the MH-1813, where predominantly registered nurses using CDSS conduct TT. ${ }^{1120}$ The nurses performing TT at MH-1813 all undergo a 6-week introduction programme, and MH-1813 conducts audits of nurse contacts. ${ }^{22}$ The CDSS triage tool is a locally developed tool with detailed guidelines divided into three main sections: somatic illness, somatic injury and psychiatric illness. The tool supports the nurses' decision-making by suggesting essential questions based on a selected symptom as well as the most accurate triage outcome. ${ }^{11}$ The Central Denmark Region has a population of 1.2 million citizens ${ }^{23}$ and the Capital Region of Denmark 1.7 million citizens. ${ }^{11}$ The nurses at MH-1813 and GPs at the GPC answer the same type of calls, as both services are the first point of contact when experiencing none life-threatening health problems outside office hours. In both regions, emergency medical services take care of the life-threatening health problems. The use of the $\mathrm{OOH}$ services in Denmark is free of charge for the callers. Potential outcomes for the triage are home visit, a consultation at an $\mathrm{OOH}$ centre or hospital, or the caller is given advice on self-care. ${ }^{11}$

\section{Selection}

The TT calls were recorded during an inclusion period of 2 weeks in November 2016. We randomly selected 200 conversations from the 1950 conversations used in the larger scale study (figure 1 displays the exclusion criteria). Exclusion criteria 1-5 were applied before inclusion, for the larger scale study, but violation of criteria $6-8$ could first be detected during the assessment process for the current study. Therefore, 125 GP triage calls and 125 nurse triage calls were randomly selected to ensure the goal of 100 nurse and 100 GP TT conversations. Inclusion stopped after assessment of 100 triage conversations in each group (figure 2).

\section{Outcome measures}

To assess the recorded triage conversations, the following outcome measures were selected: length of contact, question types, spontaneous talking time, speaking time of the triagist and speaking time of the patient, negative affect, and response to negative affect. Some of the outcome measures, such as length of contact and question types, were selected based on previous studies. ${ }^{12}$ Other measures 


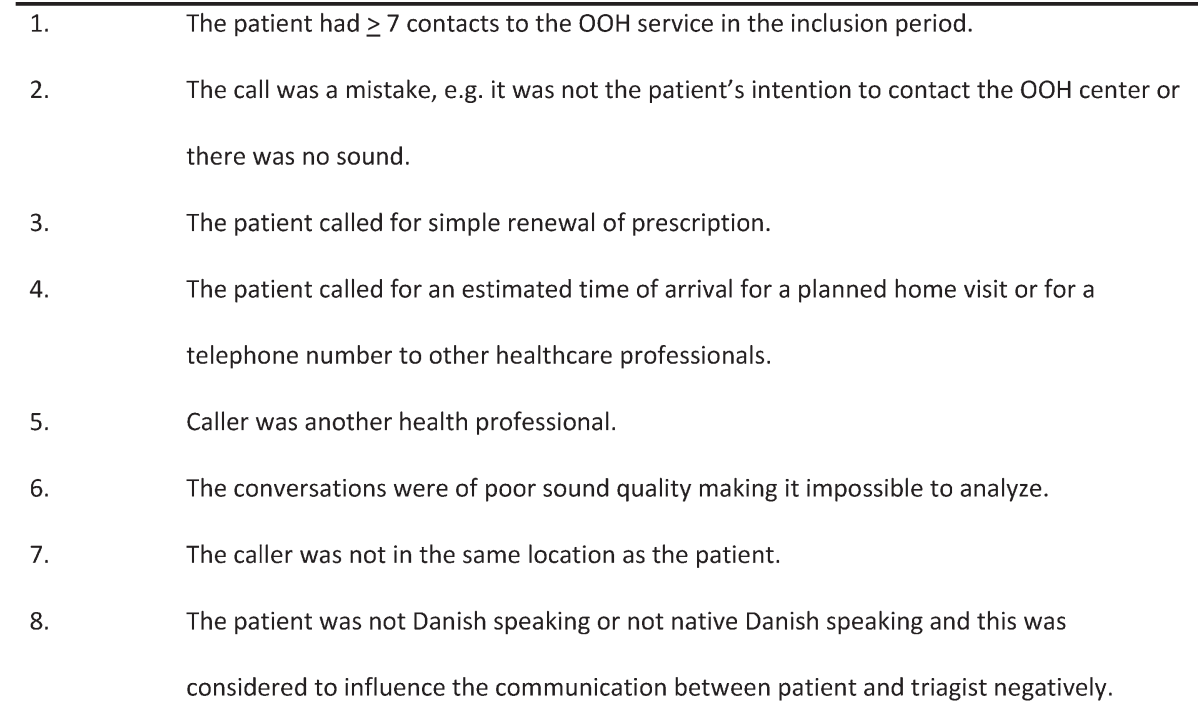

Figure 1 Exclusion criteria. $\mathrm{OOH}$, out-of-hours.

were chosen according to relevance and defined after discussion by the research group. The following were the definitions:
- Length of contact: time from start to end of a contact measured in seconds. The time nurses used to confer with a physician was included in the length of contact.

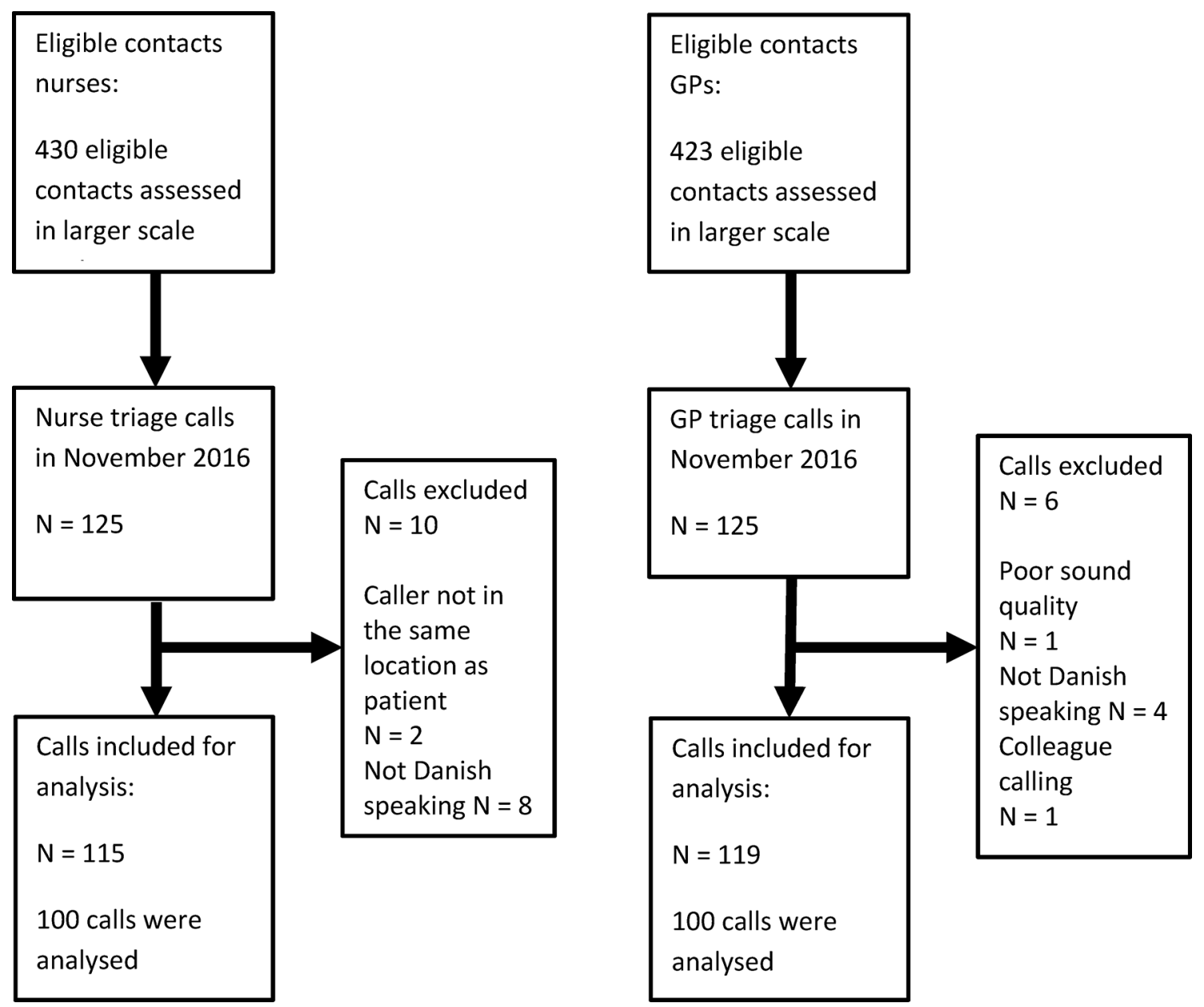

Figure 2 Flow diagram of included calls. GPs, general practitioners. 
- Question types: open-ended questions, open-ended requests, closed-ended questions and leading questions:

- Open-ended questions were defined as questions which provide a broad set of response possibilities and facilitate a further (broad) elaboration of the caller's situation or symptoms (eg, 'How can I help you?' or 'Could you please describe your pain').

- Closed-ended questions were defined as questions which limit the caller to answers such as 'yes' or 'no', a number, or a selection from a brief list of choices (eg, 'Does your foot hurt?' or 'Is the pain worse in your food, ankle or toes?').

- Leading questions were defined as questions where the triagist intentionally or unintentionally created a question, which more or less led the caller to a specific answer (eg, 'You don't have a fever, do you?').

We defined some general criteria for determining question types. First, questions were not classified based on the caller's response but the intention of the triagist. For example, if a caller answered to a closed-ended question with a detailed report, the question was still registered as 'closed-ended'. If double questions were asked, only the last question was categorised. In addition, questions/ requests about civil registration numbers, personal identification information and the caller's localisation were not registered.

- Spontaneous talking time was defined as the amount of time the caller was allowed to speak uninterruptedly by the triagist, measured from when the caller began to elaborate on the reason for contact until the interruption by the triagist. If the triagist interrupted the caller to gather his/her civil registration number, the spontaneous talking time continued if the triagist afterwards asked the caller to proceed. Supporting the caller to elaborate by using words like 'yes' and 'please go on' was included into the spontaneous talking time.

- Speaking time of the triagist and speaking time of the patient were two parameters created to assess the ratio of time the triagist and the patient spoke. Filling in medical records was included in the triagist speaking time. For nurse-led triage, time used to consult a physician or calls to plan admission to hospitals was excluded. Patient speaking time included the amount of time the patient used to think of an answer.

- Negative affect was defined as the caller's negative emotional expressions related to symptoms or the situation. The expression 'I feel pain' was not interpreted as a negative affect if the pain did not explicitly lead to a negative emotional affect, such as 'I feel pain, and it makes me scared'. The negative affect could be expressed verbally ('I am worried') or non-verbally in the form of crying burst or heavy sighs, which is also used in the Roter interaction analysis system (RIAS) model by Roter and Larson. ${ }^{24}$ Each triage conversation was classified as (1) no emotional affect, (2) spontaneously expressed negative affect and (3) invited expression of negative affect (ie, when the triagist invited the patient to express his/her emotional state). The sentences containing negative affect were transcribed and registered.

- Response to negative affect was registered when the caller had spontaneously expressed negative affect. The triagist response was classified as 'no empathic response' or 'emphatic response'. An emphatic response was defined according to the RIAS model as 'Statements that paraphrase, interpret, recognize and name the others' emotional state'. ${ }^{24}$ All responses to spontaneously expressed negative affect were transcribed and registered in order to be assessed by EV and AFP.

\section{Assessment of triage conversation}

Based on the included outcome measures, a standardised scoring scheme was developed and pilot-tested. In the pilot test, EV and DSG analysed individually five conversations, after which they discussed discrepancies. The discrepancies were minor, concerning only one question out of the five calls and did not lead to adjustments. EV analysed the remaining 200 conversations using the scoring scheme. All transcribed negative affect and triagists' responses were reviewed and scored by AFP after assessment by EV, and in case of disagreement scoring was discussed until consensus was reached.

\section{Statistical analysis}

Using the Mann-Whitney U test for non-normal distributed data and the Student's t-test for unpaired samples for normally distributed data, the following outcomes were compared between GPs and nurses: number of leading questions, closed-ended and open-ended questions, proportion of open-ended questions out of the total number of questions, duration of call, triagist's talking time, patient's talking time and patient's share of total talking time. The proportion of calls with spontaneous and requested negative affectivity among GPs and nurses was compared using the $\chi^{2}$ test. The $\mathrm{X}^{2}$ test was also used to compare the proportion of nurses' and GPs' calls in which an emphatic response followed spontaneous negative affectivity. Statistical significance was assumed for $\mathrm{p}<0.05$ and was analysed with STATA V.14.2.

\section{RESULTS}

\section{Length of contact and talking time}

Nurses had statistically significantly $(p=0.001)$ longer contacts compared with GPs (median length: nurses $=264 \mathrm{~s}$; GPs $=137 \mathrm{~s}$ ) (table 1). In $36 \%$ of nurse triage contacts, triage nurses either transferred the contact to a physician or had to confer the contact with a physician. Triage nurses allowed the patients significantly $(\mathrm{p}=0.01)$ more talking time before interrupting compared with GPs (nurses: median of 23.4s, GPs 17.9s). GPs had a median speaking time of $66.5 \mathrm{~s}$, which was significantly shorter 
Table 1 Description of communicative parameters between GP-led and nurse-led triage

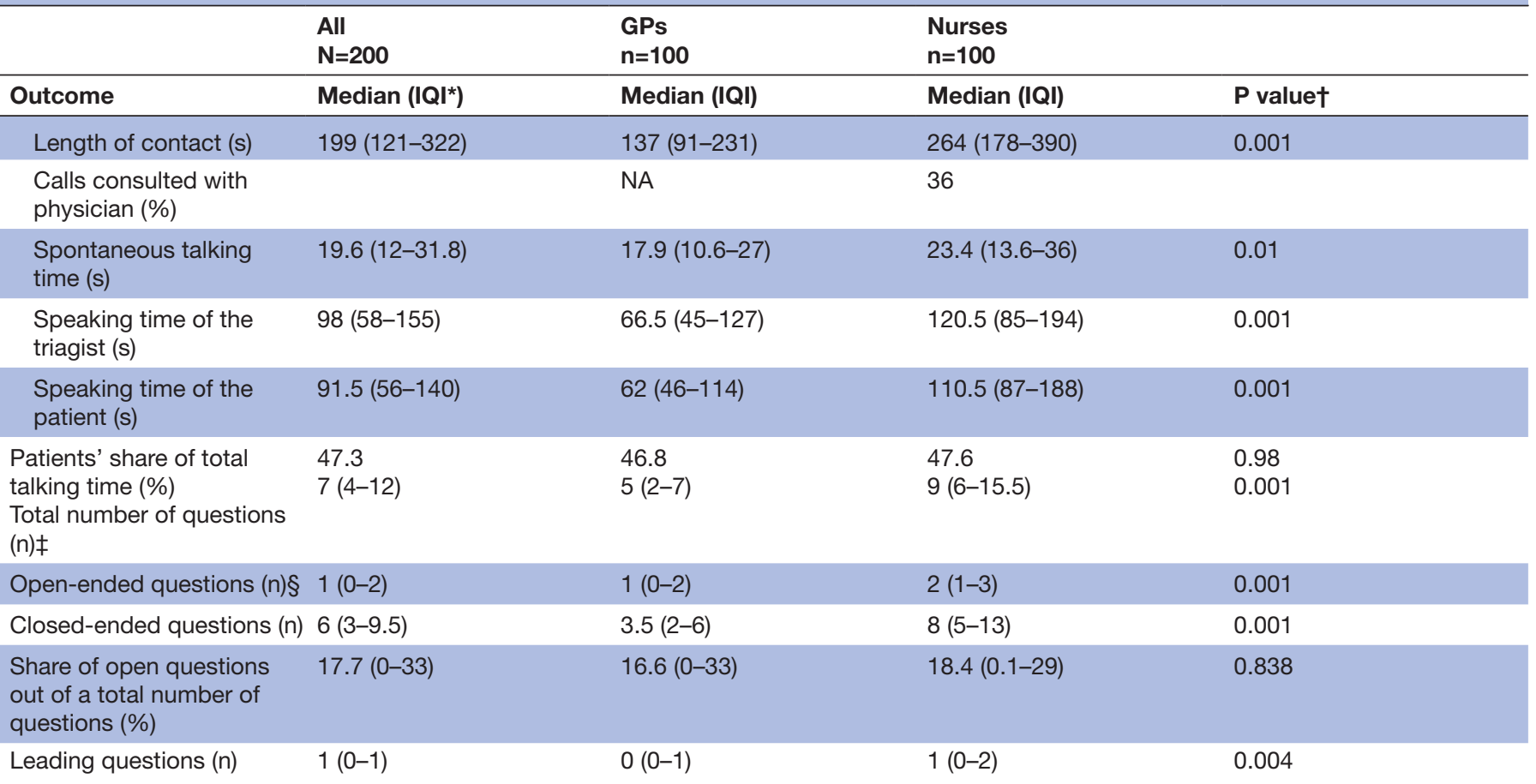

*IQI, interquartile interval (25\% and $75 \%$ percentiles).

†For difference between GPs and nurses.

$\ddagger$ Total number of questions included open-ended and closed-ended questions. Leading questions were not included.

$\S N u m b e r$ of questions.

GP, general practitioner; NA, not assessed.

than nurses who had a median speaking time of $120.5 \mathrm{~s}$. However, the difference in patients share of talking time when comparing GPs and nurses was not statistically significant $(46.8 \%$ vs $47.6 \%$, $\mathrm{p}=0.98)$.

\section{Question types}

In general nurses asked more questions than GPs $(\mathrm{p}=0.001)$. Open-ended questions represented $16.6 \%$ of GPs' total number of questions and $18.4 \%$ of nurses' (table 1). The difference was not statistically significant. Nurses used statistically significantly more closed-ended questions $(\mathrm{p}=0.001)$ and leading questions $(\mathrm{p}=0.0045)$ compared with GPs. Callers expressed negative affect in $23 \%$ of the contacts, which was independent of whether the triagist was a nurse or a GP (table 2). In $36 \%$ and $29 \%$ of contacts with expression of negative affect, GPs and nurses responded emphatically, respectively $(\mathrm{p}=0.6)$ (table 3). See box 1 for examples of emphatic versus non-emphatic response.

Callers were invited to express negative affect in 4 out of the 200 contacts, corresponding to $2 \%$. GPs requested negative affect in $3 \%$ of calls and nurses in $1 \%$, and the difference was not significant.

Table 2 Negative affect in triage calls and triagist response to spontaneously negative affect

\begin{tabular}{|c|c|c|c|c|c|}
\hline & All & General practitioners & Nurses & & \\
\hline Outcome & $\mathrm{N}=\mathbf{2 0 0}$ & $n=100$ & $n=100$ & $\mathrm{X}^{2}$ & $P$ value \\
\hline $\begin{array}{l}\text { No spontaneous } \\
\text { affect }^{\star}\end{array}$ & $154(77)$ & $78(78)$ & $76(76)$ & & \\
\hline \multirow[t]{2}{*}{ Spontaneous affect } & $46(23)$ & $22(22)$ & $24(24)$ & & \\
\hline & & & & 0.11 & 0.74 \\
\hline \multirow[t]{2}{*}{ Emphatic response } & $15(33)$ & $8(36)$ & $7(29)$ & & \\
\hline & & & & 0.27 & 0.6 \\
\hline
\end{tabular}

${ }^{*} \mathrm{n}(\%)$. 
Table 3 Requested negative affect: caller invited by triagist to elaborate on negative affect

\begin{tabular}{|c|c|c|c|c|c|}
\hline & All & General practitioners & Nurses & & \\
\hline Outcome & $\mathrm{N}=\mathbf{2 0 0}$ & $n=100$ & $n=100$ & $\mathrm{X}^{2}$ & $P$ value \\
\hline Requested affect ${ }^{\star}$ & $4(2)$ & $3(3)$ & $1(1)$ & & \\
\hline No requested affect & $196(98)$ & $97(97)$ & 99 (99) & & \\
\hline & & & & 1.02 & 0.3 \\
\hline
\end{tabular}

*n (\%).

\section{DISCUSSION}

\section{Main findings}

Compared with GPs, nurses had significantly longer telephone contacts and asked significantly more questions overall. Although nurses compared with GPs used significantly more open-ended questions, no difference was found concerning the share of open-ended questions to the total number of questions. Nurses gave callers significantly longer spontaneous talking time, but no difference was found for patients' share of total talking time. The level of spontaneous as well as invited expression of negative affect was the same in nurse-led and GP-led triage contacts. The likelihood of an emphatic response to callers' expression of negative affect appeared slightly higher for GPs $(36 \%)$ than for nurses $(29 \%)$. This difference was however not significant.

\section{Strengths and limitations}

This study is one of the first to thoroughly compare communicative parameters between GPs and nurses in $\mathrm{OOH}$ services. The use of randomly selected, real-life triage contacts reflected the diversity and challenges the triagist meets in an $\mathrm{OOH}$ centre, which is a major strength of the present study. We also used clear definitions of communicative parameters, which was lacking in previous studies on the use of open-ended questions. ${ }^{210}$ A question which proposes an answer of a 'single word structure' (eg, 'yes' or 'no') was weighted in our definition of closed-ended questions. In contrast to this

Box 1 Examples of emphatic versus non-emphatic response to a patient's expression of negative affect

- Example 1: spontaneous negative affect with an emphatic answer.

- Patient: "I am really worried. I don't know what to do."

- Triage nurse: "That is only understandable. I will do my best to help you."

- Example 2: spontaneous negative affect with a non-emphatic answer.

- Patient: "This is totally crazy. I have never experienced anything like this. I am so worried!"

- Triage nurse: "So do you have any pain in your head?"

- Example 3: requested negative affect.

- Patient: Calls about a son with a high temperature.

- GP: "Are you worried about your child? When you are a first time mother I can surely understand if you are worried."

- Patient: "Yes I am very worried about this situation."

GP: "I will do my best to help you and your son." definition, the RIAS model also includes 'When, where, how many or how long' as closed-ended questions. ${ }^{25}$ Our chosen definition of closed-ended questions might have led to an underestimation of these and a subsequent overestimation of open-ended questions. However, since this possible overestimation of open-ended questions is for both GPs and nurses, this potential overestimation has not biased the results. The study also had some limitations. First, only one rater (EV) scored the contacts. However, a pilot study of five randomly selected triage calls with two independent raters revealed near-complete agreement between the raters. Moreover, all registered expressions of negative affect were discussed by two raters to assure consensus of classification of type (spontaneous vs invited) and response (empathically/non-empathically). Differences in classification of the response (emphatically/non-emphatically) to negative affect were present in less than $2.5 \%$ of the total calls with an expression of negative affect. Second, as we lacked information on call handlers (eg, age, sex) and patients' reasons for contact and primary symptom, we could not take these aspects into account when testing differences between GPs and nurses. As triagists were kept anonymous, we were unable to cluster the analyses at the triagist level, and as a consequence assumptions of independency among observations might be violated.

\section{Comparison with existing literature}

Length of contact and speaking time

Mohammed et a ${ }^{6}$ also found that TT nurses had longer calls compared with TT GPs. However, in their study neither GPs nor nurses used CDSS, which could compromise direct comparison between the present study and their study. In contrast Murdoch et al found no difference in contact length when comparing GPs and nurses. ${ }^{12} \mathrm{We}$ suggest that use of CDSS and high percentage of calls conferred with a physician were reasons for the longer calls in nurse TT. It is unclear what the effect of call length is on effectiveness and patient safety. A short call may be efficient in the short term, but inefficient in the long term, if a patient calls again due to unmet needs. If triagists are too few, longer contacts could increase the waiting line, leading to decreased patient satisfaction ${ }^{26}$ and being a danger for seriously ill patients not having the opportunity to bypass the line. ${ }^{27}$

One Swedish study investigated reasons for malpractice claims and found the parameter 'failure to listen' was 
the most common reason. ${ }^{10}$ The median time for spontaneous talking time was approximately $20 \mathrm{~s}$ in our study. It could potentially harm patient safety, if the patient is not allowed to fully elaborate on the symptoms, which could lead to misdiagnosing. An American study reported that patients had an average of $22 \mathrm{~s}$ before being interrupted. ${ }^{21}$ They also showed that allowing the patient to finish speaking did not prolong the total consultation length. $^{21}$

\section{Question types}

In general, we found nurses to ask more questions than GPs. This might be associated with nurses having longer contacts and their use of the CDSS tool. In agreement with other studies, we found that nurses used more closed-ended than open-ended questions. ${ }^{2}{ }^{10}$ Murdoch et $a l^{12}$ found that nurses asked more questions, mainly being closed-ended, whereas GPs used more open-ended questions. This might be explained by the CDSS tool, which is designed to gather information on patients' reported symptoms often as a closed-ended question. ${ }^{12}$ We found that GPs asked relatively few questions, openended as well as closed-ended. Meyer $e t a l^{28}$ found that doctors have a high level of diagnostic confidence, with a mismatch between confidence and diagnostic accuracy. The few questions in GP triage could be a result of too high confidence, which potentially could cause inadequate anamnesis and be a risk for patient safety. For unknown reasons, we found nurses to use significantly more leading questions. Leading questions have the potential to suggest a certain answer, which may prevent the patient from delivering vital information.

\section{Negative affect}

Murdoch et al found that $43 \%$ of GP questions were directed against callers' concerns or expectations and obtaining details of medical history compared with $11 \%$ of nurse questions. ${ }^{12}$ Our results showed that GPs and nurses invited the patient to express their emotional state in less than $2 \%$ of the contacts. This is striking because worry is a frequent motive for contacting $\mathrm{OOH}$ care and increases the likelihood of being triaged to a clinical consultation. ${ }^{29}$ One study suggested that failure to listen to a caller's concern is a probable reason for errors of assessment in TT. ${ }^{10}$ One Swedish study found that triage nurses mainly responded to expression of concerns with closed-ended medical questions, and only $6 \%$ of contacts with expression of concerns had an emphatic response from the triagist. ${ }^{2}$ In our study, nurses and GPs responded with an emphatic response in $29 \%$ and $36 \%$ of contacts with spontaneous negative affect, respectively. A possible reason for nurses' lower rate of response to negative affect could be the CDSS tool. When negative affect is unhandled, callers might feel less satisfied and be prone to call again. The focus on empathic responses to expression of negative affect originates from medical literature on patient-centredness. The concept of patient-centred care is regarded as crucial for patient satisfaction and safety. ${ }^{30}$ Patient-centred communication, one of the cornerstones of patient-centred care, has been introduced as the gold standard of face-to-face consultations and is widely endorsed as a central component of high-quality healthcare. ${ }^{31}$ However, it remains unclear whether patient-centredness is also the gold standard of TT communication. Occasionally, calls to the $\mathrm{OOH}$ service concern severe acute conditions and emergencies needing for the professional to guide and direct the caller more strictly. The ultimate goal of TT is timely triage of the patient to the right level of care. Murdoch $e t$ al raised the question whether patient-centredness is the gold standard of triage communication or if this would contribute to longer triage times than considered necessary to perform the triage. ${ }^{12}$

The study hypotheses regarding TT nurses having longer contacts, using more open-ended questions and giving the caller more spontaneous talking time were confirmed. We did not confirm the hypothesis that nurses responded more emphatically to callers' expression of concern compared with TT GPs.

\section{Recommendations for practice and future research}

- Future studies are necessary to investigate the relation of length of triage contact with effectiveness and safety, to check the hypotheses of longer contacts being less efficient but more safe.

- How to improve triagist handling of negative affect is an important area for further research.

- Future studies should examine whether the included quality indicators in this study reflect patient-centredness, that is, by determining whether scores on the quality indicators associate with patient satisfaction.

- Future studies should examine whether patient-centredness is relevant to $\mathrm{OOH}$ services, for example, increases TT efficiency and patient safety.

\section{CONCLUSION}

This study demonstrated differences in communicative parameters between GP-led and nurse-led TT. Nurses had longer contacts, asked more questions and gave more spontaneous talking time to callers compared with GPs. Compared with nurses, GPs seemed to respond slightly more often emphatically to callers who spontaneously expressed negative affect, but the difference was not statistically significant. In less than $2 \%$ of the calls, the caller was invited to express his/her emotional state. Further research is needed to define high-quality TT communication and to assess the consequences of the communicative differences in relation to efficiency of $\mathrm{OOH}$ services and patient safety.

Acknowledgements The authors thank the MH-1813 and GPC organisation for contribution with regard to collection of telephone calls, and MH-1813 for the delivery of manpower for the collection of calls.

Contributors EV, DSG and AFP contributed to the conception and design of the study. EV collected the data, and EV, DSG and AFP analysed the data. EV wrote the first draft of the study, and DSG, AFP, LH and MBC provided critical revisions to the manuscript and have approved the submission of the final manuscript. 
Funding This study was part of another study supported by the Danish foundation TrygFonden, the Foundation for Primary Health Care Research (Praksisforskningsfonden) in the Central Denmark Region, the Committee for Quality Improvement and Continuing Medical Education in general practice (Kvalitets- og Efteruddannelsesudvalget) in the Central Denmark Region, and the Foundation for General Practice (Praktiserende Lægers Uddannelses- og Udviklingsfond).

Competing interests None declared.

Patient consent for publication Not required.

Ethics approval According to Danish law, the study needs no approval from the National Committee on Health Research Ethics, as it included no biomedical intervention. The project has been approved and is registered in the Record of Processing Activities at the Research Unit for General Practice in Aarhus in accordance with the provisions of the General Data Protection Regulation (GDPR).

Provenance and peer review Not commissioned; externally peer reviewed.

Data sharing statement Due to problems with safeguarding the confidentiality and anonymity of recorded patient calls and call handlers, there are no data that can be shared.

Open access This is an open access article distributed in accordance with the Creative Commons Attribution Non Commercial (CC BY-NC 4.0) license, which permits others to distribute, remix, adapt, build upon this work non-commercially, and license their derivative works on different terms, provided the original work is properly cited, appropriate credit is given, any changes made indicated, and the use is non-commercial. See: http://creativecommons.org/licenses/by-nc/4.0/.

\section{REFERENCES}

1. Huibers L, Giesen P, Wensing M, et al. Out-of-hours care in western countries: assessment of different organizational models. BMC Health Serv Res 2009;9:105.

2. Ernesäter A, Engström M, Winblad U, et al. Telephone nurses' communication and response to callers' concern--a mixed methods study. Appl Nurs Res 2016;29:116-21.

3. Huibers L, Moth G, Carlsen AH, et al. Telephone triage by GPs in outof-hours primary care in Denmark: a prospective observational study of efficiency and relevance. Br J Gen Pract 2016;66:e667-e673.

4. WHO. Patient safety. 2018 https://www.who.int/patientsafety/en/

5. Leibowitz R, Day S, Dunt D. A systematic review of the effect of different models of after-hours primary medical care services on clinical outcome, medical workload, and patient and GP satisfaction. Fam Pract 2003;20:311-7.

6. Mohammed MA, Clements G, Edwards E, et al. Factors which influence the length of an out-of-hours telephone consultation in primary care: a retrospective database study. BMC Health Serv Res 2012;12:430.

7. Christensen MB, Olesen F. Out of hours service in Denmark: evaluation five years after reform. BMJ 1998;316:1502-5.

8. Derkx HP, Rethans JJ, Maiburg BH, et al. Quality of communication during telephone triage at Dutch out-of-hours centres. Patient Educ Couns 2009;74:174-8.

9. Innes M, Skelton J, Greenfield S. A profile of communication in primary care physician telephone consultations: application of the Roter Interaction Analysis System. Br J Gen Pract 2006;56:363-8.

10. Ernesäter A, Winblad U, Engström M, et al. Malpractice claims regarding calls to Swedish telephone advice nursing: what went wrong and why? J Telemed Telecare 2012;18:379-83.

11. Gamst-Jensen H, Lippert FK, Egerod I. Under-triage in telephone consultation is related to non-normative symptom description and interpersonal communication: a mixed methods study. Scand J Trauma Resusc Emerg Med 2017;25:52.
12. Murdoch J, Barnes R, Pooler J, et al. Question design in nurse-led and GP-led telephone triage for same-day appointment requests: a comparative investigation. BMJ Open 2014;4:e004515.

13. Murdoch J, Barnes R, Pooler J, et al. The impact of using computer decision-support software in primary care nurse-led telephone triage: interactional dilemmas and conversational consequences. Soc Sci Med 2015;126:36-47.

14. Derkx HP, Rethans JJ, Knottnerus JA, et al. Assessing communication skills of clinical call handlers working at an out-ofhours centre: development of the RICE rating scale. $\mathrm{Br} J$ Gen Pract 2007;57:383-7.

15. Huibers L, Moth G, Andersen M, et al. Consumption in out-ofhours health care: Danes double Dutch? Scand J Prim Health Care 2014;32:44-50.

16. Smits M, Rutten M, Keizer E, et al. The Development and Performance of After-Hours Primary Care in the Netherlands: A Narrative Review. Ann Intern Med 2017;166:737-42.

17. lacobucci G. GP out-of-hours services struggle to fill shifts amid "intense" winter pressure. BMJ 2018;360:k97.

18. Campbell JL, Fletcher $\mathrm{E}$, Britten N, et al. The clinical effectiveness and cost-effectiveness of telephone triage for managing same-day consultation requests in general practice: a cluster randomised controlled trial comparing general practitioner-led and nurse-led management systems with usual care (the ESTEEM trial). Health Technol Assess 2015;19:1-212.

19. Richards DA, Meakins J, Tawfik J, et al. Nurse telephone triage for same day appointments in general practice: multiple interrupted time series trial of effect on workload and costs. BMJ 2002;325:1214.

20. DR. BAGGRUND Sygeplejersker, ventetid og fejl har givet akutlinjen 1813 modvind fra starten. 1813 https://www.dr.dk/nyheder/indland/ baggrund-sygeplejersker-ventetid-og-fejl-har-givet-akutlinjen-1813modvind-fra

21. Langewitz W, Denz M, Keller A, et al. Spontaneous talking time at start of consultation in outpatient clinic: cohort study. BMJ 2002;325:682-3.

22. Graversen DS, Pedersen AF, Carlsen AH, et al. Quality of outof-hours telephone triage by general practitioners and nurses: development and testing of the AQTT - an assessment tool measuring communication, patient safety and efficiency. Scand $J$ Prim Health Care 2019;37:18-29.

23. The Central Denmark Region. Demographic information [Internet]. [cited 2018 Jan 21]. Available from: https://www.rm.dk/regionaludvikling/regionen-i-tal/

24. October TW, Dizon ZB, Roter DL. Is it my turn to speak? An analysis of the dialogue in the family-physician intensive care unit conference. Patient Educ Couns 2018;101:647-52.

25. Roter D, Larson S. The Roter interaction analysis system (RIAS): utility and flexibility for analysis of medical interactions. Patient Educ Couns 2002;46:243-51.

26. Tranberg $\mathrm{M}$, Vedsted $\mathrm{P}$, Bech $\mathrm{BH}$, et al. Factors associated with low patient satisfaction in out-of-hours primary care in Denmark - a population-based cross-sectional study. BMC Fam Pract 2018;19:15

27. Ebert JF, Huibers L, Lippert FK, et al. Development and evaluation of an "emergency access button" in Danish out-of-hours primary care: a study protocol of a randomized controlled trial. BMC Health Serv Res 2017;17:379.

28. Meyer AN, Payne VL, Meeks DW, et al. Physicians' diagnostic accuracy, confidence, and resource requests: a vignette study. JAMA Intern Med 2013;173:1952-8.

29. Gamst-Jensen H, Huibers L, Pedersen K, et al. Self-rated worry in acute care telephone triage: a mixed-methods study. Br J Gen Pract 2018;68:e197-e203.

30. Mead N, Bower P. Patient-centredness: a conceptual framework and review of the empirical literature. Soc Sci Med 2000;51:1087-110.

31. Epstein RM, Franks P, Fiscella K, et al. Measuring patient-centered communication in patient-physician consultations: theoretical and practical issues. Soc Sci Med 2005;61:1516-28. 